\title{
EFEITO DO CULTIVO ORGÂNICO E CONVENCIONAL SOBRE A VIDA-DE-PRATELEI- RA DE ALFACE AMERICANA (Lactuca sativa L.) MINIMAMENTE PROCESSADA ${ }^{1}$
}

\author{
Júlio César MELLO², Renato DIETRICH², Elza Maria MEINERT³ ${ }^{3}$ Evanilda TEIXEIRA ${ }^{3}$,
}

Edna Regina AMANTE ${ }^{3, *}$

\begin{abstract}
RESUMO
A alface americana (Lactuca sativa), minimamente processada, foi avaliada quanto aos efeitos dos diferentes sistemas de cultivo (orgânico e convencional), sobre a vida-de-prateleira. A alface minimamente processada foi embalada em sacos de polietileno de baixa densidade (PEBD), armazenada em refrigerador a $4^{\circ} \mathrm{C}$ e avaliada até o final da vida-de-prateleira, estabelecida por métodos sensoriais. As avaliações foram realizadas durante a estocagem, nas condições pré-estabelecidas. Nos tempos zero a dez dias, uma equipe sensorial treinada avaliou a alface quanto a: cor, brilho, escurecimento enzimático, aroma, odor estranho, textura e sabor (escores de zero a dez). O teste sensorial determinou que o escore seis (6) eliminaria a amostra; a alface orgânica, atingiu o escore mínimo em tempo superior ao da alface convencional, tendo sido sensivelmente superior a esta em todos os atributos testados.

Palavras-chave: alface; vida-de-prateleira; cultivo orgânico; cultivo convencional.
\end{abstract}

\section{SUMMARY}

EFFECT OF THE ORGANIC AND CONVENTIONAL CULTIVE IN THE SHELF LIFE OF ICEBERG LETTUCE (Lactuca sativa L.) MINIMALLY PROCESSED. Iceberg lettuce (Lactuca sativa) obtained by conventional and organic cultivation systems and minimally processed was evaluated for the effect of different cultivation systems on shelf life. The minimally processed lettuce was packed in low-density polyethylene bags, stored in refrigerator at $4^{\circ} \mathrm{C}$ and evaluated until the end of shelf life period established by a sensorial team. The evaluation was performed during the storage period under pre-determined conditions. At days zero and ten, a skilled sensorial team evaluated the lettuce for: color, brightness, enzymatic darkening, flavor, off flavor, texture and smell (scores $0-10$ ). The sensorial team determined that score six (6) would eliminate the sample; the organic lettuce took longer to reach the minimum score compared to the conventional lettuce and proved substantially superior to the latter regarding all the attributes tested.

Keywords: lettuce; shelf life; organic harvesting; conventional harvesting.

\section{1 - INTRODUÇÃO}

A alface é uma cultura hortícola de grande valor alimentar, constituindo-se em componente imprescindivel das saladas, onde representa a quarta horticola em importância, ficando logo a seguir a batata, tomate e cebola em ordem de importância, tanto pela área ocupada quanto pelo valor das produções [20].

O consumo per capita catarinense de alface é de $1,5 \mathrm{~kg} /$ ano, superior ao consumo médio per capita brasileiro $(1,2 \mathrm{~kg} / \mathrm{ano})$, considerado baixo pela Organização Mundial da Saúde [12].

A alface americana vem sendo introduzida nos últimos anos como conseqüência do aumento do número de redes de lanches prontos para consumo, uma vez que estas utilizam preferencialmente a alface americana.

Dados da EPAGRI (Empresa de Pesquisa Agropecuária de Santa Catarina) revelaram que o Estado plantou em 1999 cerca de 234 hectares de alface, considerando a repetição de área. Essa produção foi praticada em 638 pequenas propriedades rurais. Utilizando em torno de 3.400 pessoas somente no setor de produção [8].

O número de refeições prontas oferecidas ao mercado vem crescendo com o interesse pela agricultura orgâ-

\footnotetext{
Recebido para publicação em 06/06/2002. Aceito para publicação em 17/02/2003 (000845).

${ }^{2}$ Empresa de Pesquisa Agropecuária de Santa Catarina

${ }^{3}$ Departamento de Ciência e Tecnologia de Alimentos, Centro de Ciências Agrárias, Universidade Federal de Santa Catarina, Florianópolis, SC, Brasil.

* A quem a correspondência deve ser enviada.
}

nica, ou agroecológica. Em virtude da oferta destes vegetais, é possivel o consumidor escolher entre o produto orgânico e o convencional. No entanto, a não ser pelas diferenças práticas entre os dois tipos de cultivo, a contribuição para o meio ambiente e a saúde dos consumidores com o consumo de vegetais orgânicos, não existem dados indicando os resultados do cultivo orgânico sobre as propriedades sensoriais dos vegetais cultivados sob o sistema orgânico e convencional.

Considerando a importância crescente tanto da alface americana minimamente processada quanto dos vegetais orgânicos, o presente trabalho mostra, através das variações nas propriedades sensoriais durante a estocagem, o efeito do cultivo orgânico e convencional sobre a vida-de-prateleira da alface americana minimamente processada.

\section{1 - Alface orgânica minimamente processada}

A alface é uma das poucas hortaliças consumidas exclusivamente in natura. Ela é indispensável na composição das saladas dos brasileiros. Embora não sendo uma das melhores fontes de vitaminas, sais minerais e outros constituintes, seu baixo valor calórico a credencia para todas as dietas [20].

\subsection{1 - Cultivo orgânico e convencional de horticolas}

A agricultura orgânica é definida como a produção de alimentos de origem vegetal e animal sem a utilização de agrotóxicos e adubos químicos sintéticos ou outros agentes contaminantes, através de um conjunto de sis- 
temas de produção com enfoque holístico, que buscam a maximização dos beneficios sociais, a auto-sustentação, a redução/eliminação da dependência de insumos, energia não renovável e a preservação do meio ambiente através da otimização do uso de recursos naturais e sócio-econômicos disponiveis [10].

No Brasil, cerca de 2.000 produtores dedicam-se especialmente à Agricultura Orgânica. O Estado de São Paulo é o pioneiro nesta área, tendo a Associação de Agricultura Orgânica (AAO) dado grande incentivo e atendido diversos produtores na orientação técnica e credenciamento de propriedades orgânicas. O Instituto Biodinâmico, instalado em Botucatu, no mesmo Estado, é responsável pela certificação de propriedades Orgânicas/Biodinâmicas no Brasil. A Estância Demétria, na mesma cidade paulista, é uma propriedade dedicada à exploração orgânica na área de Horticultura [10].

A produção de hortaliças orgânicas é atualmente a atividade mais praticada no Brasil. Por serem produtos consumidos em sua maior parte in natura, necessita que sejam puros e saudáveis, sendo esta uma exigência crescente da sociedade [10].

Os produtores dedicados ao cultivo de hortaliças orgânicas, geralmente são pequenos agricultores, e procuram nesta atividade uma fonte de renda, bem como, buscam a diversificação das atividades da propriedade. Por outro lado, tem-se observado que as camadas sociais de maior poder aquisitivo são as que tem procurado, em maior escala, os vegetais minimamente processados de produtores orgânicos. No entanto, estes produtos deverão ser popularizados. Por isso, os preços a serem praticados devem ser competitivos, igualando-se aos das hortaliças convencionais [10].

\subsection{2 - Vegetais minimamente processados}

O processamento mínimo de hortaliças refere-se às operações que eliminam as partes não comestiveis tais como cascas, talos e sementes. O corte em tamanhos menores das hortaliças, tornando-as prontas para consumo imediato, sem que a mesma venha perder a condição de produto fresco ou in natura também caracteriza esse processo [7].

Todas as hortaliças minimamente processadas são pereciveis e demonstram rápida perda da qualidade póscolheita, mesmo em temperaturas baixas durante a estocagem. Os vegetais minimamente processados são mais pereciveis do que os similares frescos. Isso ocorre devido aos danos causados aos tecidos das hortaliças resultantes das operações do processamento. Este produto, também denominado pré-cortado, pré-preparado, preparado cortado, de conveniência e fresco cortado, é um produto com valor agregado superior ao in natura não manipulado [23].

Os produtos de 4a geração também denominados minimamente processados estão representados por vegetais crus, submetidos a tratamentos de descascamento, higienização e corte. São produtos prontos para consumo e devem ser conservados em embalagens na presen- ça de ar ou de atmosfera modificada ou de uma atmosfera rarefeita $[5,6,18]$. A refrigeração com uma temperatura entre 4 e $5^{\circ} \mathrm{C}$ é indispensável [5, 13]. Nessas condições, a duração é de 4 a 10 dias dependendo do produto.

O hábito alimentar da população, em geral, vem sendo modificado, o que faz com que o mercado de alimentos atue de modo a melhorar os produtos que serão encaminhados para este público $[13,18]$. Os fatores que influenciam o comportamento do consumidor, na hora da compra, são inúmeros e se baseiam na segurança, saúde, sabor, comodidade de utilização, imaginação, marca e conotação cultural [13, 18].

Atualmente, o consumidor é o principal foco do negócio agro-alimentar. Por isso, acompanhar as mudanças de comportamento da população é de fundamental importância. Dessa maneira, passa-se a atender ao mercado conforme suas necessidades [19].

\subsection{3 - Vida-de-prateleira de vegetais}

Vida-de-prateleira de um produto alimentício é o período de tempo decorrido entre sua produção ou manipulação e àquele em que o produto conserva suas características de qualidade próprias para o consumo. Durante esse periodo o produto se caracteriza pelo nivel satisfatório de qualidade [3].

A vida-de-prateleira varia com o tipo de alimento, temperatura de estocagem e embalagem utilizada. Devem ser observados alguns danos que interferem no tempo de armazenagem dos alimentos, tais como: contaminação microbiana, contaminação por insetos e roedores, oxidação, hidrólise e reversão em gorduras, oxidação de pigmentos, reações de escurecimento não-enzimático, alterações devido ao ganho de umidade, atividade enzimática, perda de valor nutritivo, interações com os recipientes e perda da qualidade estética [3].

Os fatores bioquímicos correspondem a um amplo percentual de contribuição na estabilidade de hortaliças pós-colheita. Os vegetais respondem de formas diferenciadas às condições de cultivo, colheita, transporte, elaboração e estocagem [4].

As situações que produzem ruptura nos tecidos promovem ativação metabólica, produzindo como principais manifestações fisiológicas, um aumento na velocidade da respiração e em alguns casos, produção de etileno. As respostas dos tecidos dependem da magnitude do estresse a que foram submetidos, assim como, as tensões que produzem danos nos tecidos favorecem também a susceptibilidade dos tecidos vegetais ao etileno [26].

Mudanças na textura ocorrem, normalmente, durante crescimento e desenvolvimento e envolvem mudanças na estrutura da parede celular ou através de desordens fisiológicas. Essas alterações ocorrem devido a mudanças químicas dos componentes da parede celular primária, como celulose, pectina e hemicelulose [21].

Enzimas e substratos estão localizados em diferentes compartimentos celulares e seus transportes entre 
compartimentos são ativamente controlados. Quando ocorrem lesões nos tecidos, pelo processamento, ocorre destruição das células superficiais e alteração dos tecidos subjacentes. As reações enzimáticas produzem alterações sensoriais, como "off-flavor" (aromas estranhos), descoloração e perda de firmeza [26].

O "off-flavor" é causado principalmente pela peroxidação. A peroxidação enzimática dos ácidos graxos insaturados é o mais grave processo bioquimico modificador do aroma das hortaliças minimamente processadas. A peroxidação é catalisada por enzimas oxidantes de lipídeos com a formação de aldeídos e cetonas [9, 26].

O sabor é influenciado pela quantidade de carboidratos, ácidos orgânicos, aminoácidos, lipídeos e fenóis. Os sabores e odores desagradáveis são iniciados com a respiração anaeróbia [9].

A principal descoloração que ocorre, em tecidos lesionados, é o escurecimento enzimático e não enzimático, que ainda não estão totalmente elucidados [26]. Essas reações ocorrem em contato com o oxigênio, que promove o desenvolvimento de tonalidades rosáceas, pardas ou negras. A velocidade dessas reações depende de diversos fatores, tais como: espécie, momento da colheita e temperatura [9].

A perda da cor verde em vegetais processados e armazenados é devido à degradação da clorofila [9]. A conversão de clorofila em feofitina é uma reação de descoloração originada da acidificação do citoplasma celular, ou pela destruição provocada pela clorofilase, ativada pelo aumento de etileno [26].

Os carotenóides, importantes do ponto de vista nutricional e sensorial, são degradados pela ação do etileno, que acelera sua biossintese nesse momento e pela ação do oxigênio, que reduz suas concentrações [9].

A perda de firmeza das hortaliças é devida aos danos ocasionados no corte das células, que liberam enzimas proteoliticas e pectinoliticas que podem difundir no interior dos tecidos. O etileno pode aumentar a permeabilidade das membranas e reduzir a biossintese de fosfolipídios, o que pode interferir na integridade da membrana e da conseqüente estrutura celular [9, 26]. A decomposição das moléculas poliméricas como protopectinas, celuloses, hemiceluloses e amido, amacia as paredes celulares, pois diminui a força coesiva que mantém as células unidas [4].

A textura dos vegetais é dada pela rigidez do tecido, sem que implique em dureza. O endurecimento que sofrem os tecidos está ligado ao metabolismo dos fenóis e à lignificação [9].

Alterações dos alimentos podem ser causadas pelo crescimento microbiano e se caracterizam pelo aspecto desagradável na cor, textura, odor e sabor. A incidência dos microrganismos nos vegetais reflete a qualidade sanitária de cada etapa do processamento e as condições microbiológicas do produto cru no momento do processo [9]. A microflora responsável pela alteração dos vege- tais minimamente processados inclui um grande número de espécies bacterianas e fúngicas. Entre as Gramnegativas há um predomínio de pseudomonáceas e de enterobacteriáceas e entre as bactérias Gram-positivas, as bactérias ácido lácticas e também leveduras [26].

\subsection{4 - Aspectos sensoriais}

Por definição, a análise sensorial envolve a medida e a avaliação das propriedades sensoriais dos alimentos e materiais. Segundo o IFT (Institute of Food Tecnhologists), análise sensorial é a disciplina utilizada para definir, medir, analisar e interpretar reações produzidas pelas características dos materiais e percebidas pelos órgãos da visão, olfato, paladar, tato e audição [17].

A análise sensorial é uma ciência multidisciplinar na qual julgadores humanos usam os sentidos da visão, olfação, audição, gustação e tato para medir as características sensoriais e a aceitabilidade dos produtos alimentícios e de outros materiais. Não existe nenhum outro instrumento que possa reproduzir ou representar a resposta humana. Portanto, a evolução sensorial resulta num fator importante para qualquer estudo sobre alimentos [25].

A avaliação sensorial proporciona informação integral sobre a qualidade dos alimentos. Quando um consumidor seleciona um alimento, está de alguma forma, julgando se as características do produto satisfazem suas expectativas e se estas correspondem as suas exigências [24]

Os métodos descritivos relatam sensorialmente o produto. Isto significa definir os atributos importantes de um alimento (sabor, textura, odor, etc.) e medir a intensidade de tais atributos. Estas análises utilizam equipes com no mínimo oito julgadores treinados. Neste grupo encontram-se as análises de Perfil de Sabor, Perfil de Textura, Análise Descritiva Quantitativa (ADQ) e Perfil Livre [17].

A aceitação de um produto pelo consumidor se baseia em critérios importantes de seleção como, estágio vegetativo, frescura, crocância, aroma e aparência. Em segundo lugar vem o valor nutricional e o preço [2].

A qualidade da alface processada deve ser avaliada quanto a aparência, intensidade da cor, aspectos morfológicos e não pode exalar odores estranhos. Como são componentes diferentes para a qualidade visual total, eles pretendem ser informativos para estabelecer a importância relativa de cada defeito [14].

A análise sensorial poderá predizer o tempo de conservação da alface, definindo uma margem que representará a vida-de-prateleira desse produto [2].

\section{2 - MATERIAL E MÉTODOS}

\section{1 - Matéria-prima}

A alface americana foi cultivada em 4 áreas distintas para cada um dos dois sistemas. As respectivas áreas 
de cada sistema foram divididas em 7 estratos, cada um representando um tempo de exposição em prateleira. De cada um dos 4 estratos de cada sistema, foi amostrada uma combinação de 3 plantas por estrato. De cada combinação foram extraídas ao acaso 5 amostras, compostas por 3 folhas de alface. Portanto: 2 sistemas $\times 7$ tempos de exposição x 5 amostras totalizando 70 unidades experimentais, as quais foram embaladas em sacos de polietileno de baixa densidade (PEBD), mantidas na temperatura de $4^{\circ} \mathrm{C}$ e a $85 \%$ de umidade relativa do ar, na ausência de luz.

\subsection{1 - Detalhes do sistema de produção de al- face americana}

A produção de alface americana foi conduzida de forma similar à realizada por produtores tradicionais de alface americana orgânica e convencional. Foi usada a tecnologia do cultivo protegido para minimizar o efeito do clima sobre os cultivos.

- Sistema de produção orgânica

A produção orgânica da alface americana foi obtida segundo as normas técnicas estabelecidas pelo INSTITUTO BIODINÂMICO [11].

Com 60 dias para o transplante, foram corrigidos os niveis de fertilidade do solo, usando de fosfato natural $100 \mathrm{~g} / \mathrm{m}^{2}$ de canteiro, conforme resultado da análise de solo.

Aos 30 dias antes do plantio foi realizada a adubação orgânica usando $2 \mathrm{~kg}$ de esterco bovino por metro quadrado de canteiro.

Após 44 dias da emergência das plântulas, o transplante foi realizado quando estas apresentavam em média quatro folhas definitivas.

Durante o cultivo foram realizadas capinas manuais para a eliminação de plantas concorrentes.

Também foram realizadas duas adubações orgânicas de cobertura, sendo que a primeira foi aos 32 dias após o transplante usando 1,0 litro de biofertilizante por $\mathrm{m}^{2}$ de canteiro e a segunda cobertura aos 60 dias após o transplante onde foram usados mais 1,0 litros do biofertilizante por metro quadrado de canteiro.

\section{- Sistema de produção convencional}

A produção convencional de alface americana foi realizada segundo recomendação dos órgãos de assistência técnica do Estado de Santa Catarina [16].

Trinta dias antes do plantio foi aplicado $2 \mathrm{~kg}$ de cama de aviário (3 lotes de frango/cama) por metro quadrado de canteiro.

A cama de aviário é produzida com uma forragem espalhada homogeneamente no piso do aviário, normalmente composta por cepilho ou serragem. Após três ciclos de engorda de frangos, esta cama apresenta uma quantidade apreciável de nutrientes, que pode ser usada como adubo agricola.
Quatorze dias antes do transplante, foi realizada uma adubação química com 150 g de adubo da fórmula $5-20$ - 10 (5\% de nitrogênio, $20 \%$ de fósforo e $10 \%$ de potássio) por metro quadrado de canteiro.

O transplante foi realizado 44 dias após a semeadura, quando as mudas apresentavam em média 4 folhas definitivas por planta.

O espaçamento de plantio usado foi de $30 \times 30 \mathrm{~cm}$ entre plantas.

Os canteiros para cultivo definitivo foram dimensionados com 1,25 metros de largura por 10 metros de comprimento e 15 centimetros de altura.

Foi realizada irrigação por micro-aspersão usando mangueira agrícola de marca Santeno, modelo II. A vazão utilizada foi de 13 litros por metro de tubo, monitorada por tensiômetro de solo instalado a 15 e $30 \mathrm{~cm}$ de profundidade. Quando o vacuômetro do equipamento acusava 200 milimetros de coluna de água, era iniciada a irrigação. Assim que o tensiômetro voltasse a indicar zero milimetro de coluna de água era suspensa a irrigação.

Foram realizadas capinas manuais para a eliminação de todas as plantas concorrentes.

Durante o ciclo vegetativo foram realizadas duas adubações de cobertura com nitrogênio e cálcio. A primeira aos 32 dias após o transplante, onde foram aplicados 60 gramas de nitrato de cálcio/ $\mathrm{m}^{2}$ de canteiro e a segunda adubação aos 60 dias após o transplante usando 75 gramas de nitrato de cálcio/ $\mathrm{m}^{2}$ de canteiro.

\section{2 - Colheita e pós-colheita}

A colheita ocorreu com 75 dias após o transplante, tanto para a alface cultivo orgânico quanto para a alface cultivo convencional, quando as mesmas apresentavam boa compacidade da "cabeça" e um bom desenvolvimento vegetativo para a espécie.

Com auxilio da tabela de números aleatórios foram colhidas 96 plantas nas quatro áreas para todo o experimento, sendo 48 plantas do sistema orgânico e 48 plantas do sistema convencional.

As alfaces foram colhidas com um corte transversal no caule, junto ao solo, desprezando as folhas "baixeiras" danificadas ou acometidas por fitopatologias.

As alfaces foram acondicionadas em caixas plásticas apropriadas para colheita, identificadas pelo sistema de cultivo. Em seguida foram levadas para a recepção da unidade de processamento.

\section{3 - Processamento}

\subsection{1 - Área suja}

O produto foi recepcionado e separado por sistema mantendo um fluxo continuo dentro da unidade.

Cada alface sofreu toalete manual retirando-se as folhas externas mais verdes e o caule. 
As alfaces foram lavadas por 3 minutos em água potável a $15^{\circ} \mathrm{C}$ para a retirada de solo e material orgânico aderido.

Em seguida, o produto foi levado para a área limpa em caixas higienizadas e identificadas.

\subsection{2 - Área limpa}

Toda a área de trabalho, equipamentos e utensilios foram sanitizados com uma solução de hipoclorito de sódio a 50ppm de CA (cloro ativo).

Os manipuladores, durante todo o processo, usaram guarda-pós, luvas, gorros e máscaras.

Durante todo o tempo de processamento não foi permitida a entrada de pessoas estranhas na área limpa.

Foi utilizada água potável para a produção de gelo e para o processamento. Nas mudanças dos tempos de análise e entre os sistemas de cultivo, a água foi trocada e resfriada com gelo.

As alfaces foram desfolhadas e selecionadas manualmente; somente as folhas da parte interna da planta seguiram para o processamento.

As folhas das alfaces foram sanitizadas por $3 \mathrm{minu}-$ tos, em um tanque de PVC com 50L de água tratada com $100 \mathrm{ppm}$ de cloro ativo, a temperatura entre de 1 a $4^{\circ} \mathrm{C}$.

Em seguida foram imersas por 3 minutos em água potável com temperatura entre 1 e $4^{\circ} \mathrm{C}$, para retirar o excesso de cloro.

As folhas foram retiradas com auxilio de uma caixa vazada e levadas para a centrifugação por 45 segundos a $450 \mathrm{rpm}$ (rotações por minuto).

Foram colocadas três folhas de alface centrifugada por embalagem de polietileno de baixa densidade (PEBD), previamente numeradas e pesadas em balança semi-analitica.

A selagem das embalagens foi realizada à quente em atmosfera normal, usando uma seladora convencional, marca Turbovac, modelo 450-S.

O produto embalado foi estocado em refrigerador vertical e monitorado com termohigrógrafo, para manter a temperatura de $4^{\circ} \mathrm{C}$ e $80 \%$ de umidade relativa do ar, na ausência de luz.

\subsection{3 - Embalagem}

O filme escolhido para este experimento foi o polietileno de baixa densidade (PEBD), usado comumente no empacotamento de vegetais minimamente processados (Tabela 1).

\section{4 - Análise sensorial}

As avaliações sensoriais das alfaces americanas minimamente processadas foram programadas para serem aplicadas ao longo de 14 dias, através do teste de avaliação descritiva quantitativa - ADQ, por equipe treinada no Departamento de Ciência e Tecnologia de Alimentos do Centro de Ciências Agrárias da Universidade Federal de Santa Catarina.
TABELA 1. Características da embalagem de PEBD empregadas para o acondicionamento das amostras de alfaces orgânica e convencional

\begin{tabular}{lc}
\hline Comprimento $(\mathrm{mm})$ & 280 \\
Largura $(\mathrm{mm})$ & 200 \\
Espessura $(\mathrm{mm})$ & 0,08 \\
Área total de difusão $\left(\mathrm{m}^{2}\right)$ & 0,112 \\
Peso $(\mathrm{g})$ & 4,58 \\
Volume médio de gases $(\mathrm{mL})$ & 930 \\
Permeabilidade ao $\mathrm{O}_{2}\left(\mathrm{~cm}^{3} \mathrm{~m}^{-2} \cdot \mathrm{dia}^{-1}\right.$ a 1 atm a $25^{\circ} \mathrm{C}, 45 \%$ UR) & 3.900 a 13.000 \\
Permeabilidade ao $\mathrm{CO}_{2}\left(\mathrm{~cm}^{3} \mathrm{~m}^{-2} \cdot \mathrm{dia}^{-1}\right.$ a 1 atm a $25^{\circ} \mathrm{C}, 45 \%$ UR) & 7.700 a 77.000 \\
Permeabilidade ao vapor d'água $\left(\mathrm{g} \cdot \mathrm{m}^{-2} \cdot \mathrm{dia}^{-1}\right.$ a $37,8^{\circ} \mathrm{C}$ e $90 \%$ UR) & 6 a 23,2 \\
\hline
\end{tabular}

$\mathrm{UR}=$ Umidade Relativa

Foram utilizados quinze julgadores para o treinamento com alface americana minimamente processada.

As caracteristicas sensoriais relevantes do produto a ser analisado foram identificadas e discutidas em consenso com a equipe de julgadores em quatro sessões de duas horas. Foram estabelecidos os descritores e significados de cada um dos atributos testados segundo as normas da ABNT [1], e durante o treinamento foram estabelecidos.

A cor avaliada visualmente através da embalagem de verde-escuro (escore zero) a verde-claro (escore 10).

O brilho avaliado visualmente através da embalagem de opaco (escore zero) a brilhante (escore 10).

O escurecimento enzimático também avaliado visualmente através da embalagem com pigmento ferruginoso (escore zero) a sem pigmento ferruginoso (escore 10).

O aroma avaliado através da inalação depois de aberta a embalagem de folha deteriorada (escore zero) a folha fresca (escore 10).

O odor estranho avaliado através da inalação depois de aberta a embalagem de intenso (escore zero) a ausente (escore 10).

A textura avaliada através da crocância apresentada na nervura central da folha de tipo manga madura (escore zero) a maçã madura crocante (escore 10).

O sabor avaliado pela degustação do vegetal de amargo (escore zero) a adocicado (escore 10).

As amostras foram apresentadas em embalagens seladas e codificadas, contendo 3 folhas de alface minimamente processada. Cada julgador recebeu duas embalagens, sendo uma do sistema orgânico e a outra do sistema convencional. As amostras foram servidas para todos os julgadores com água mineral sem gás.

As tomadas amostrais foram realizadas no tempo zero, 3ㅇ, 6, 8, 10 dia da estocagem, para os dois sistemas (alface americana orgânica e alface americana convencional).

Com auxilio de escala horizontal não estruturada, os julgadores analisaram a intensidade percebida em cada atributo solicitado.

A extremidade esquerda da reta representa o conceito péssimo na percepção do julgador e a extremidade direita excelente. 
$\mathrm{O}$ indice de aceitabilidade da alface minimamente processada nos dois sistemas, foi calculado a partir das médias dos atributos ao longo do tempo.

Foi estabelecido que a alface minimamente processada seria considerada aceita em termos de suas propriedades sensoriais para compra e consumo, quando atingisse um indice de no minimo $60 \%$ da avaliação média dos atributos determinados previamente pelos julgadores.

\section{5 - Análise estatística}

Análise de regressão linear e análise de variância foram empregadas para a comparação dos resultados dos dois sistemas de cultivo, empregando o sistema SAS (Statistical Analysis System), versão 6.12 [22].

\section{3 - RESULTADOS E DISCUSSÃO}

Os resultados das avaliações da alface americana minimamente processada cultivada no sistema orgânico e convencional, quanto aos atributos: cor, brilho, escurecimento enzimático, aroma, odor estranho, textura e sabor, são apresentados na Tabela 2.

A vida-de-prateleira seguiu um limite mínimo de aceitabilidade para os diferentes atributos estudados. Ficou determinado pelos julgadores que o valor seis (6) seria o escore minimo de aceitabilidade do produto, ou seja, de desclassificação. Limite estabelecido em treinamento dos julgadores, segundo o que prescreve as normas da ABNT [1].

As amostras foram oferecidas para degustação até o décimo dia de exposição nas condições previstas no experimento.

Dentre todos os atributos avaliados o escurecimento enzimático foi o mais sensivel, para o qual desde o tempo zero, ocorreu superioridade de escore estatisticamente significativo para a alface orgânica.

O comportamento da deterioração das folhas de alface, medido pelo escurecimento enzimático, foi semelhante para os dois sistemas de cultivo (Figura 1), porém como o escurecimento enzimático tem como limite o escore 6 ou $60 \%$, aplicando-se as duas equações constantes na Figura 1. Este limite foi atingido pelo sistema orgânico onde para $X=8$ dias de prateleira, temos $Y=6,10$ enquanto que no sistema convencional atingiu-se este valor já no 6 o dia de prateleira, onde para $X=6$, obtivemos $Y=6,02$. Portanto, sob o ponto de vista do escurecimento enzimático, o sistema orgânico foi mais eficiente, superando a vida-de-prateleira convencional em dois dias.

A deterioração das folhas de alface, cada dia a mais na prateleira, medida através do escurecimento enzimático, diminuiu 0,43 e 0,38 unidades por dia de prateleira, a partir de 10 unidades na escala considerada, para os sistemas orgânico e convencional respectivamente (Figura 1).

O escurecimento enzimático mostrou um comportamento linear explicando $\left(\mathrm{R}^{2}\right)$ em $99 \%$ para o sistema orgânico e 95\% para o sistema convencional.
TABELA 2. Escores médios conferidos aos atributos da análise sensorial da alface americana minimamente processada no sistema orgânico e convencional, ao longo do tempo.

\begin{tabular}{|c|c|c|c|c|c|c|}
\hline \multirow{2}{*}{$\begin{array}{l}\text { Escores } \\
(0 \text { a 10) }\end{array}$} & \multirow{2}{*}{ Sistemas } & \multicolumn{5}{|c|}{ Tempo de prateleira (dias) ${ }^{*}$} \\
\hline & & Zero & 3 & 6 & 8 & 10 \\
\hline Cor & $\begin{array}{l}\text { orgânic } \\
\text { convenc }\end{array}$ & $\begin{array}{l}9,29^{\mathrm{a}} \\
9,56^{\mathrm{a}}\end{array}$ & $\begin{array}{l}9,10^{\mathrm{a}} \\
8.49^{\mathrm{a}}\end{array}$ & $\begin{array}{l}8,53^{\mathrm{a}} \\
8,22^{\mathrm{a}}\end{array}$ & $\begin{array}{l}8,44^{\mathrm{a}} \\
6,96^{\mathrm{b}}\end{array}$ & $\begin{array}{l}7,80^{\mathrm{a}} \\
6,54^{\mathrm{b}}\end{array}$ \\
\hline Brilho & $\begin{array}{l}\text { orgânic } \\
\text { convenc }\end{array}$ & $\begin{array}{l}9,29^{a} \\
9,24^{a}\end{array}$ & $\begin{array}{l}8,65^{\mathrm{a}} \\
7,89^{\mathrm{b}}\end{array}$ & $\begin{array}{l}7,49^{a} \\
6,87^{b}\end{array}$ & $\begin{array}{l}6,94^{\mathrm{a}} \\
6,08^{\mathrm{b}}\end{array}$ & $\begin{array}{l}6,25^{\mathrm{a}} \\
5,50^{\mathrm{b}}\end{array}$ \\
\hline $\begin{array}{l}\text { Escurecimento } \\
\text { enzimático }\end{array}$ & $\begin{array}{l}\text { orgânic } \\
\text { conven }\end{array}$ & $\begin{array}{l}9,66^{\mathrm{a}} \\
8,76^{\mathrm{b}}\end{array}$ & $\begin{array}{l}8,13^{\mathrm{a}} \\
6,70^{\mathrm{b}}\end{array}$ & $\begin{array}{l}7,11^{\mathrm{a}} \\
5,78^{\mathrm{b}}\end{array}$ & $\begin{array}{l}5,88^{\mathrm{a}} \\
5,34^{\mathrm{b}}\end{array}$ & $\begin{array}{l}5,36^{\mathrm{a}} \\
4,69^{\mathrm{b}}\end{array}$ \\
\hline Aroma & $\begin{array}{l}\text { orgânic } \\
\text { conven }\end{array}$ & $\begin{array}{l}9,79^{\mathrm{a}} \\
9,23^{\mathrm{a}}\end{array}$ & $\begin{array}{l}8,76^{\mathrm{a}} \\
8,14^{\mathrm{b}}\end{array}$ & $\begin{array}{l}8,09^{\mathrm{a}} \\
7,17^{\mathrm{b}}\end{array}$ & $\begin{array}{l}7,16^{\mathrm{a}} \\
6,44^{\mathrm{b}}\end{array}$ & $\begin{array}{l}6,47^{\mathrm{a}} \\
5,41^{\mathrm{b}}\end{array}$ \\
\hline Odor & orgânic & $9,77^{a}$ & $9,20^{\mathrm{a}}$ & $8,82^{a}$ & $8,33^{\mathrm{a}}$ & $7,87^{\mathrm{a}}$ \\
\hline Estranho & conven & $9,57^{\mathrm{a}}$ & $9,31^{a}$ & $8,76^{\mathrm{a}}$ & $8,53^{a}$ & $8,10^{a}$ \\
\hline Textura & $\begin{array}{l}\text { orgânic } \\
\text { conven }\end{array}$ & $\begin{array}{l}9,63^{\mathrm{a}} \\
9.44^{\mathrm{a}}\end{array}$ & $\begin{array}{l}9,01^{\mathrm{a}} \\
905^{\mathrm{a}}\end{array}$ & $\begin{array}{l}8,24^{\mathrm{a}} \\
8.02^{\mathrm{a}}\end{array}$ & $7,78^{\mathrm{a}}$ & $7,24^{a}$ \\
\hline Sabor & $\begin{array}{l}\text { orgânic } \\
\text { conven }\end{array}$ & $9,64^{\mathrm{a}}$ & $\begin{array}{l}9,10^{\mathrm{a}} \\
8,66^{\mathrm{a}}\end{array}$ & $\begin{array}{l}8,52^{\mathrm{a}} \\
7,97^{\mathrm{b}}\end{array}$ & $\begin{array}{l}7,93^{\mathrm{a}} \\
7,33^{\mathrm{b}}\end{array}$ & $\begin{array}{l}7,39^{\mathrm{a}} \\
6,89^{\mathrm{b}}\end{array}$ \\
\hline
\end{tabular}

${ }^{*}$ Letras diferentes entre linhas em um mesmo atributo e tempo, indicam diferenças estatisticamente significativas para $\alpha=0,05$.

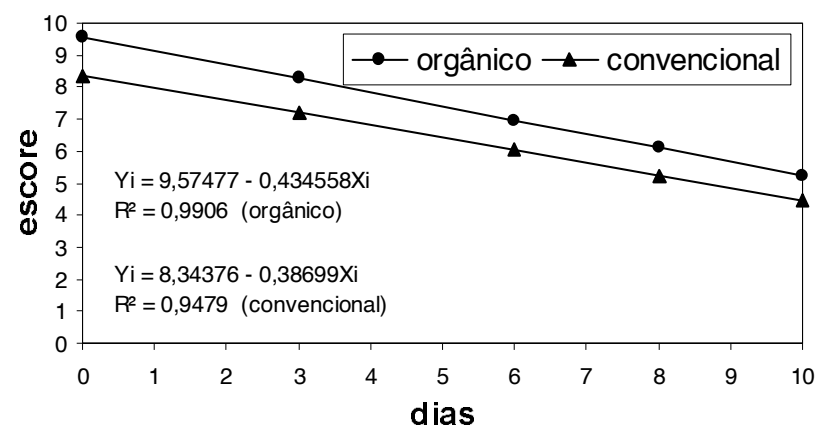

FIGURA 1. Escores dados para o atributo escurecimento enzimático da alface americana minimamente processada, no sistema orgânico e convencional, ao longo do tempo de prateleira.

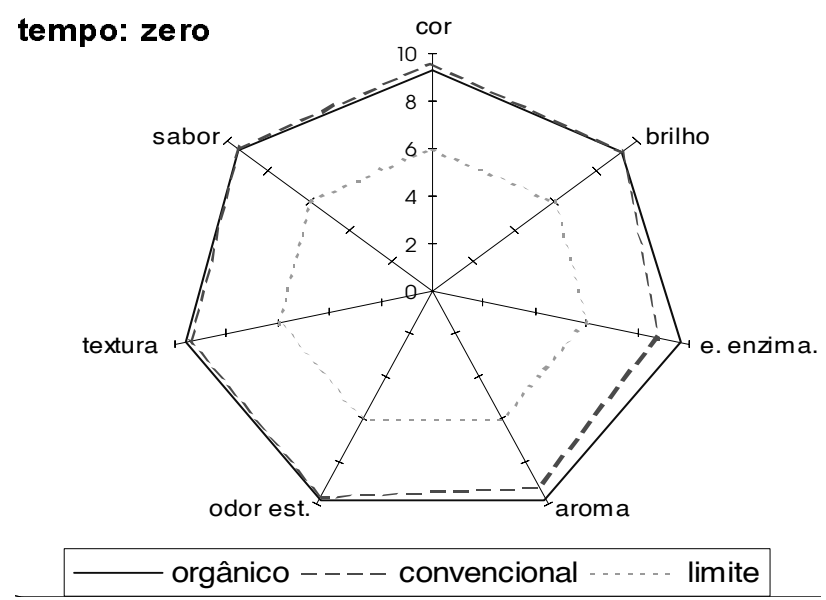

FIGURA 2. Análise sensorial dos atributos da alface americana minimamente processada, no sistema orgânico e convencional, no tempo zero.

No tempo zero de estocagem, a alface convencional superou a alface orgânica no atributo cor (Figura 2). No entanto, a alface orgânica foi superior nos demais atri- 
butos. Em alface, a clorofila consiste no principal pigmento responsável pela cor. Este é alterado mediante diferentes fatores isolados ou em conjunto. Segundo CHITARRA \& CHITARRA [4], variações no $\mathrm{pH}$, devido ao aumento da concentração de ácidos orgânicos nos vacúolos, ativação da enzima clorofilase e sistemas oxidantes endógenos, contribuem para a perda da cor.

No decorrer do período de exposição, no terceiro dia, a alface orgânica superou a alface convencional quanto à cor (Figura 3).

A alface orgânica foi superior quanto ao brilho desde o tempo zero até o final da exposição (Figuras 2, 3, 4, 5 e ). Esta importante diferença entre os dois sistemas de cultivos sugere que a estrutura das células vegetais, bem como a interação entre água e matéria seca na alface de maior brilho é mais intensa. Provavelmente, os sólidos solúveis e os compostos que se ligam com a água, tais como pectina, hemicelulose e outros estiveram em maior concentração na alface orgânica.

\section{tempo: 3 dias}

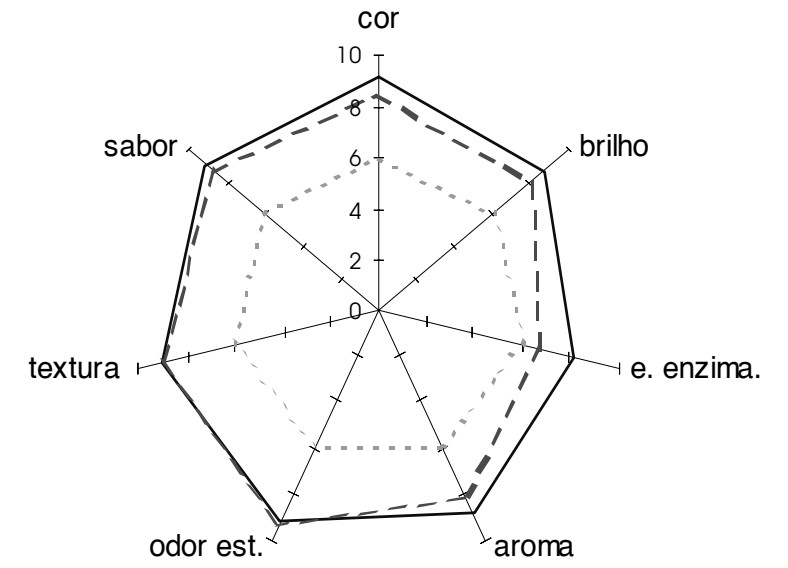

—orgânico - - - convencional . . . . . - limite

FIGURA 3. Análise sensorial dos atributos da alface americana minimamente processada, no sistema orgânico e convencional, no terceiro dia.

No sexto dia de exposição foi observado que a alface convencional entrou no limite do atributo pré-estabelecido pelos provadores, enquanto que a alface orgânica apresentou condições superiores de aceitabilidade.

Neste mesmo tempo de análise, observou-se que os atributos brilho e aroma aceleraram em direção à desclassificação, com a alface orgânica mantendo condições de superioridade em relação à convencional ( Figura 4).

No oitavo dia de exposição foi observado que o atributo escurecimento enzimático para alface orgânica ultrapassou o limite da aceitabilidade do produto, determinando o máximo de vida-de-prateleira. Os atributos aroma e brilho nos dois sistemas, também estavam próximos do limite de aceitabilidade (Figura 5).

\section{tempo: 6 dias}

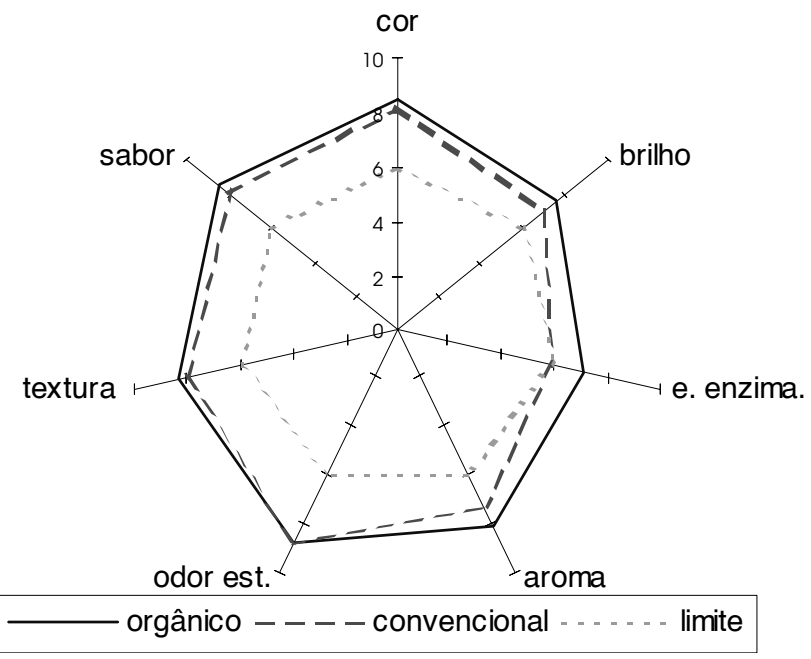

FIGURA 4. Análise sensorial dos atributos da alface americana minimamente processada, no sistema orgânico e convencional, no sexto dia.

\section{tempo: 8 dias}

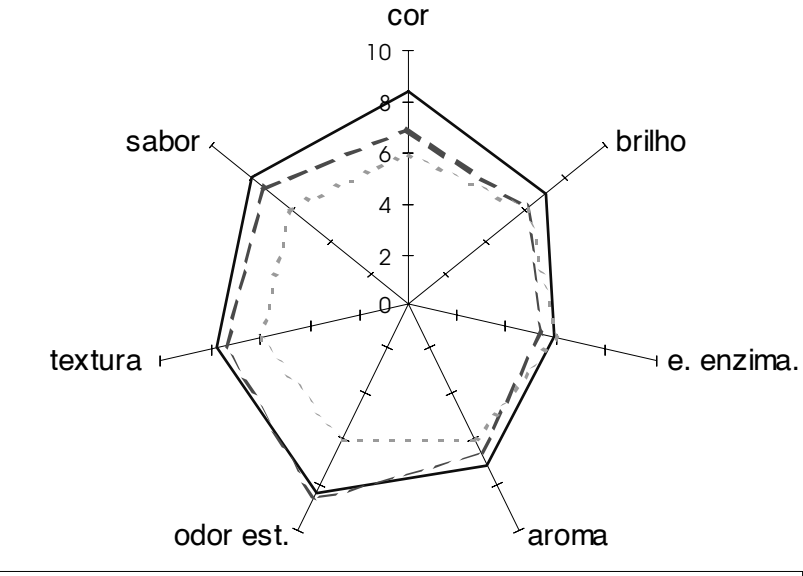

FIGURA 5. Análise sensorial dos atributos da alface americana minimamente processada, no sistema orgânico e convencional, no oitavo dia.

No décimo dia de análises, além do atributo escurecimento enzimático para os dois sistemas determinarem o final da análise, os atributos aroma e brilho do sistema convencional, também cruzaram o limite de aceitabilidade (Figura 6).

O escurecimento enzimático é estimulado por danos fisicos na folha. Uma vez que a alface convencional foi a que apresentou menores escores para a textura, podese atribuir a fragilidade da folha a maior tendência ao escurecimento enzimático.

Folhas mais frágeis são menos brilhantes, o que foi verificado pelos menores escores para o atributo brilho para alface convencional. 


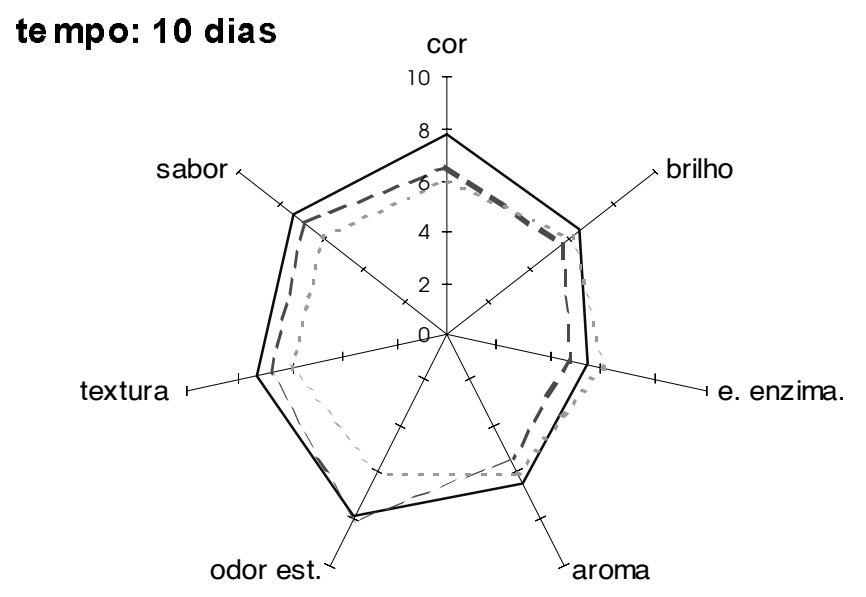

orgânico - - - convencional limite

FIGURA 6. Análise sensorial dos atributos da alface americana minimamente processada, no sistema orgânico e convencional, no décimo dia.

A maior fragilidade das folhas também se apresenta como indicativo de substratos mais facilmente sujeitos às alterações de natureza enzimática, não visualizada pelos provadores e que interferem no aroma do produto. Durante a estocagem, enzimas despolimerizantes e desesterificantes endógenas atuam alterando a textura dos vegetais.

A literatura é escassa quanto a trabalhos comparando produtos de cultivo orgânico, com o cultivo convencional, porém, as publicações sobre alterações pós-colheita oferecem subsídios para estas discussões.

Quanto ao sabor, o maior teor de matéria seca encontrado por MELLO [25] para alface orgânica, após o terceiro dia de exposição justificou a sensivel diferença entre os dois sistemas de cultivo.

Todos os atributos analisados apresentaram uma tendência à regressão linear, dando uma ligeira vantagem ao sistema de cultivo orgânico da alface americana minimamente processada, exceto quanto ao atributo odor estranho, que não apresentou diferença significativa entre os dois sistemas. Portanto, as diferenças observadas provavelmente não são devidas à presença de contaminação microbiana, uma vez que as amostras dos sistemas de cultivo avaliados, seguiram o mesmo tratamento pós-colheita.

A perda de textura associada a alterações de cor e aroma são processos que ocorrem em maior ou menor intensidade segundo a natureza química dos vegetais. A alface orgânica mostrou-se sensivelmente diferente da alface convencional, desencadeando estes processos de natureza química e enzimática mais lentamente do que a alface convencional.

\section{4 - CONCLUSÕES}

- O sistema de cultivo orgânico permitiu, nas condições testadas, ampliar sensivelmente o tempo de vida-de-prateleira da alface americana minimamente processada.

- A alface americana cultivada sob o sistema orgânico superou a alface americana convencional quanto ao tempo de vida-de-prateleira em dois dias.

- A avaliação sensorial mostrou sensivel superioridade para a alface americana minimamente processada produzida no sistema orgânico em relação à convencional.

\section{5 - REFERÊNCIAS BIBLIOGRÁFICAS}

[1] ABNT - ASSOCIAÇÃO BRASILEIRA DE NORMAS TÉCNICAS. Alimentos e Bebidas - Análise Sensorial - Testes de análise descritiva quantitativa, 1998.

[2] BALLESTEROS, F. R. Poscosecha del Tomate para consumo en fresco. In: NUEZ, F. El cultivo del tomate. Barcelona: Mundi-Prensa, 1995, p. 589-623.

[3] CABRAL, A.C.D.; FERNANDES, M.H.C. Aspectos Gerais sobre a Vida-de-Prateleira de Produtos Alimentícios. Boletim do Ital, Campinas, v. 17, n. 4, p. 371-439, out./ dez., 1980.

[4] CHITARRA, M. I. F.; CHITARRA, A. B. Pós-colheita de frutos e hortaliças: fisiologia e manuseio. Lavras: ESAL/ FAEPE, 1990. 293p.

[5] CPRC - Comité Permanent de la Restauration Collective. Cuisine centrale... Horizon 2001. Paris: Les Nouvelles du Monde, Cahier n. 18, 1989.

[6] CPRC - Comité Permanent de la Restauration Collective. L'agro-alimentaire au service de la restauration collective. Paris: Les Nouvelles du Monde, Cahier n. 14, 1985.

[7] EMATER/DF. Vegetais minimamente processados. Brasília, 1997. 19p.

[8] EPAGRI. Levantamento da produção de hortícolas de Santa Catarina. Itajaí, 24p. 1999. trabalho não publicado.

[9] GIMENO, R. M. G.; COSANO, G. Z.; LÓPEZ, M. A. Conservación de los alimentos mediante atmósfera modificada. Vegetales de IV gama. Alimentaría, v. 267, p. $89-104,1995$

[10] HAMERSCHMIDT, I. Agricultura orgânica: conceituações e princípios. In: Anais do $38^{\circ}$ CONGRESSO BRASILEIRO DE OLERICULTURA. Petrolina-PE: ART\&MIDIA, 1998. CD - ROM.

[11] INSTITUTO BIODINÂMICO. Diretrizes para os padrões de qualidade biodinâmico, Deméter e orgânico. 5.ed. Botucatu, 1995. 26p.

[12] IBGE. Censo agropecuário. Rio de Janeiro, 1989.

[13] LAGRANGE, L. La commercialisation des products agricoles et alimentaires. 2 ed. Paris: TecDoc, 1995, $445 \mathrm{p}$.

[14] LÓpez-Galvez, G.; SAltveit, M.; CANTwell, M. The visual quality of minimally processed lettuces stored in air or controlled atmospheres which emphasis on romaine and iceberg types. Postharvest Biology and Technology, Davis, v. 8, p. 179-190, 1996.

[15] Mello, J. C.; BRAUn, R. L. \& MATOS FILHO, A. M. A cultura das folhosas. Empresa de Pesquisa Agropecuária do Estado de Santa Catarina, 1998. 29 pág.

[16] MELLO, J. C. Vida de prateleira da alface americana (Lactuca sativa L.) minimamente processada sob cultivo orgânico e convencional. Dissertação de mestra- 
do em Ciência dos Alimentos, Universidade Federal de Santa Catarina, 2001.

[17] PEREIRA, C. F. \& AMARAL, A. P. A aplicação da análise sensorial na indústria de alimentos. Alimentos \& Tecnologia, n. 72, Ed. Isabella Marcondes Piason, 1997.

[18] PROENÇA, R. P. C. Inovação tecnológica na producão de alimentação coletiva. Florianópolis: Insular, 1997. 135p.

[19] REVISTA SUPERHIPER. "Como cativar o cliente do ano 2.000". São Paulo. n. 237, ano 21, p. 162, maio de 1995.

[20] RIPADO, M. F. B. A alface: a chicória frisada e a escarela. Lisboa: F. Franco. [199?]. 77p.

[21] SAMS, C. E. Preharvest factors affecting postharvest texture. Postharvest Biology and Technology, Davis, v. 15, n. 3, p. 249-254, 1999.
[22] SAS INSTITUTE INC. Sas's user guide. Version 6.12 edition. Cary, NC, SAS Institute Inc., 1996.

[23] SCHLimme, D. V; ROONEY, M. L. Packaging of minimally processed fruits and vegetables. In: WILEY, R.C Minimally processed refrigerated fruits and vegetables. New York: Chapman \& Hall, 1994. p. 135-182.

[24] TEIXEIRA, E.; MAINERT, E.; BARBETTA, P. Análise sensorial de alimentos. Florianópolis: 1987. 180 p.

[25] WATTS, B.M. Métodos sensoriales básicos para la evaluación de alimentos. Ottawa: CIID, 1992. 170p.

[26] WILEY, R. C. Frutas y hortalizas mínimamente procesadas y refrigeradas. Tradução por José Fernández-Salguero Carretero. Zaragoza: Ed. Acribia, 1997. 362p. Tradução de: Minimally Processed Refrigerated Fruits \& Vegetables. 